\title{
Editorial: Fitness of Marine Calcifiers in the Future Acidifying Ocean
}

\author{
Jonathan Y. S. Leung ${ }^{1,2 *}$, Ben P. Harvey ${ }^{3}$ and Bayden D. Russell ${ }^{4}$ \\ ${ }^{1}$ Faculty of Materials and Energy, Southwest University, Chongqing, China, ${ }^{2}$ Southern Seas Ecology Laboratories, School of \\ Biological Sciences, The Environment Institute, The University of Adelaide, Adelaide, SA, Australia, ${ }^{3}$ Shimoda Marine \\ Research Center, University of Tsukuba, Shimoda, Japan, ${ }^{4}$ The Swire Institute of Marine Science and School of Biological \\ Sciences, The University of Hong Kong, Hong Kong, SAR China
}

Keywords: adaptation, biomineralization, calcification, climate change, fitness and survival, marine organism, ocean acidification

\section{Editorial on the Research Topic}

Fitness of Marine Calcifiers in the Future Acidifying Ocean

\section{INTRODUCTION}

Over the last century, anthropogenic $\mathrm{CO}_{2}$ emissions via combustion of fossil fuels have caused drastic changes in oceans with sea surface temperatures increasing steadily due to global warming. In addition to ocean warming, seawater has become more acidic as more $\mathrm{CO}_{2}$ is dissolved into the world's oceans (IPCC, 2019). As $\mathrm{CO}_{2}$ emissions are forecast to accelerate in the future (Caldeira and Wickett, 2005), understanding how marine organisms are influenced by ocean acidification (OA) and warming has received substantial attention (Doney et al., 2009). Organisms which build calcareous structures for growth and protection (e.g., coccolithophores, corals, gastropods, bivalves,

OPEN ACCESS

Edited by:

Carlos M. Duarte

King Abdullah University of Science and Technology, Saudi Arabia

Reviewed by:

Nelson A. Lagos,

Universidad Santo Tomás, Chile

*Correspondence:

Jonathan Y. S. Leung jonathan.leung@adelaide.edu.au

Specialty section:

This article was submitted to Global Change and the Future Ocean, a section of the journal Frontiers in Marine Science

Received: 03 August 2021

Accepted: 30 August 2021

Published: 23 September 2021

Citation:

Leung JYS, Harvey BP and Russell BD (2021) Editorial: Fitness of Marine Calcifiers in the Future Acidifying Ocean. Front. Mar. Sci. 8:752635. doi: 10.3389/fmars.2021.752635 and sea urchins) are of particular concern because OA is expected to make calcification more energy-demanding and increase dissolution of calcareous structures (Harvey et al., 2018; Byrne and Fitzer, 2019). Consequently, the fitness and survival of marine calcifiers could be reduced, possibly affecting the integrity of marine ecosystems in view of their abundance, diversity, and ecological functions in oceans.

There is now a large body of literature which demonstrates that calcifiers can indeed be impaired by $\mathrm{OA}$ in various aspects, such as physiology, calcification, growth, and survival (Harvey et al., 2013). Nevertheless, growing evidence reveals that some calcifiers can prevail in the $\mathrm{CO}_{2}$-acidified environment and produce durable calcareous structures (e.g., Leung et al., 2019, 2020a; Di Giglio et al., 2020), implying their resistance and adaptability to OA. Thus, more comprehensive studies are needed to decipher how calcifiers adjust or succumb to OA and how warming modulates the impacts of OA on calcifiers. We brought together this Research Topic to address these issues and provide better insights into the fate of calcifiers in future marine ecosystems.

\section{SUMMARY OF THE STUDIES IN THIS SPECIAL ISSUE}

Ocean acidification is expected to undermine calcification (or shell building) due to the decreased carbonate saturation state and increased acidity of seawater (Byrne and Fitzer, 2019). Yet, calcification is a physiological process and thus can be affected by temperature (Clark et al., 2020), possibly leading to unexpected outcomes when warming interacts with OA. For example, crystallographic disorientation during calcification can be caused by warming in the mussel Mytilus edulis, but OA can mitigate this adverse effect (Knights et al.). Using 3D microcomputed tomography, Chatzinikolaou et al. observed that the gastropod Nassarius nitidus formed thinner and more porous shells under OA, but these negative effects disappeared when exposed to combined $\mathrm{OA}$ and warming. In contrast, the gastropod Columbella rustica 
produced thicker and denser shells under warming; however, when combined with $\mathrm{OA}$, the shells became thinner and more porous (Chatzinikolaou et al.). These findings clearly indicate the species-specific nature of responses to OA and warming, probably driven by the differences in physiology among calcifiers. Identifying the mechanisms underlying the mixed responses of calcifiers to OA and warming is important to shed light on their fitness and survival in future oceans. For example, since energy is required for calcification, altering the energy allocated for calcification may underlie the response of calcifiers to future seawater conditions (Leung et al., 2020b). By studying resistant corals that can survive in the $\mathrm{CO}_{2}$-acidified environment, Agostini et al. found that they had a higher potential for energy production and inherent capacity to allocate more energy for calcification than the sensitive corals. This finding not only helps explain the inconsistent responses of calcifiers to OA, but also implies that OA-sensitive species would be replaced by OAresistant species in future oceans.

It is noteworthy that short-term experiments (typically $<3$ months) using organisms within a single generation have been predominantly used for OA research due to the inherent logistical constraints of longer experiments. Despite the scientific merits, these studies could underestimate the capacity of calcifiers to accommodate future seawater conditions via long-term and multi-generational exposure (Zhao et al., 2019; Cornwall et al., 2020; Leung et al., 2021). Thus, research on transgenerational plasticity (i.e., phenotypic change in offspring in response to the environmental stress experienced by parents) is of particular interest. In this Special Issue, Harianto et al. revealed that parental exposure of the urchin Heliocidaris erythrogramma to warming for 3 months can elevate the metabolic rate of offspring as juveniles, which may facilitate their persistence to warming. By conducting transplant experiments, Kurihara et al. showed that adult coral Pocillopora acuta inhibiting the $\mathrm{CO}_{2}$-acidified habitat not only had higher calcification and net photosynthetic rates than those under control conditions, but also their larvae had higher lipid and chlorophyll contents (c.f. control larvae reared under high- $\mathrm{CO}_{2}$ conditions) that indicate greater energy availability and tolerance to OA. These results suggest that transgenerational acclimatization can be a critical mechanism allowing calcifiers to survive under future seawater conditions, which cannot be unraveled by short-term experiments.

\section{CURRENT UNDERSTANDING AND FUTURE RESEARCH DIRECTIONS FOR MARINE CALCIFIERS UNDER OCEAN ACIDIFICATION}

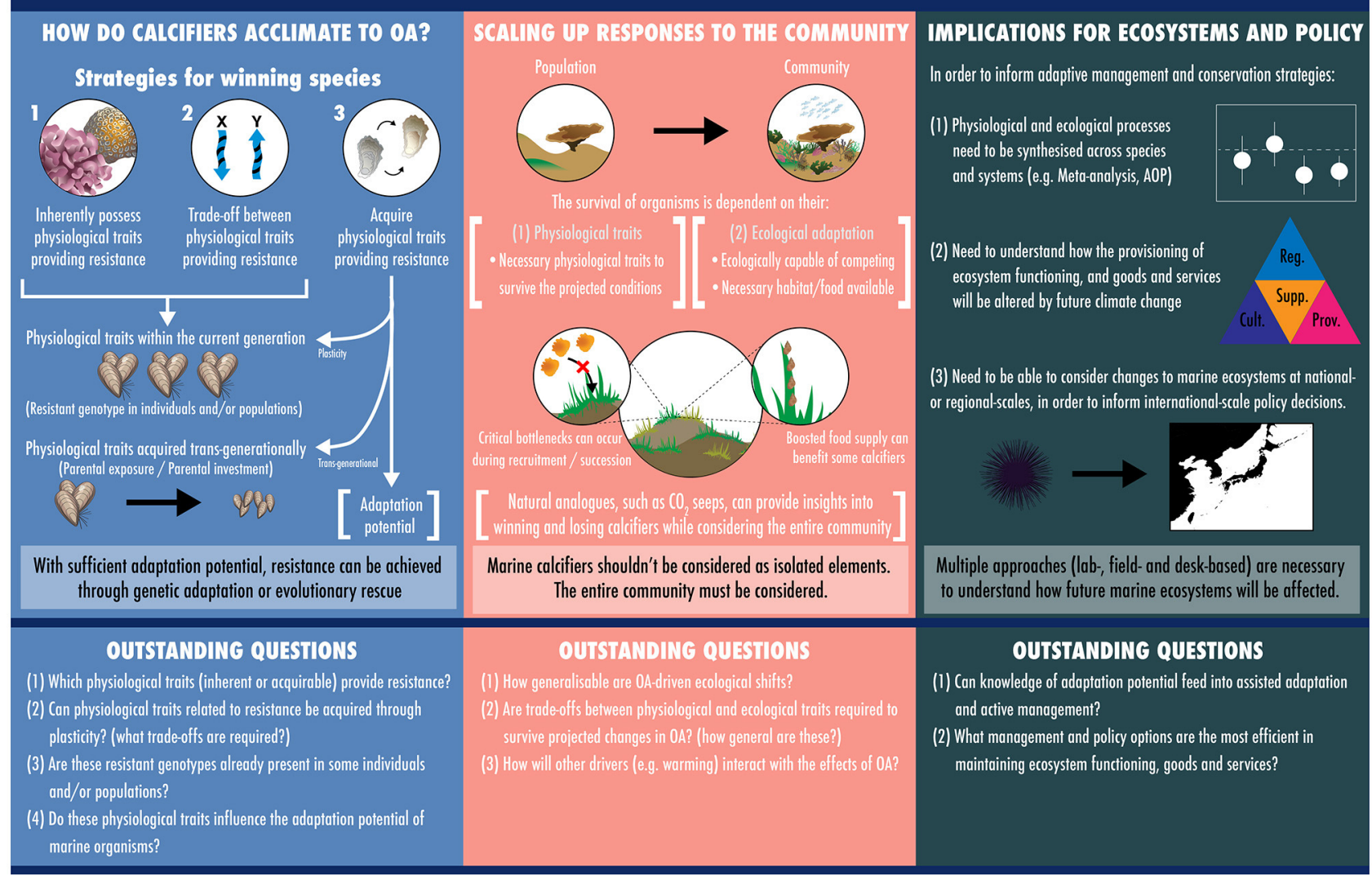

FIGURE 1 | Suggested future research directions to understand how ocean acidification affects the fitness and survival of marine calcifiers by considering adaptation potential and species interaction in the community, with implications for management of ecosystems. 
Although calcifiers can exhibit compensatory responses (e.g., phenotypic plasticity) to counter the impacts of climate change (Leung et al., 2017; Peck et al., 2018; Glazier et al., 2020; Wang et al., 2020), trade-offs against other biological processes are often incurred. For instance, the coral Galaxea fascicularis can accommodate OA by sustaining photosynthetic performance, but the nitrogen fixation machinery is compromised as a trade-off, possibly affecting coral resilience to OA (Zheng et al.). In addition, plastic responses to climate change may not always be exhibited, depending on phenotypes. Minuti et al. showed metabolic acclimation of the gastropod Trochus maculatus to OA and warming by boosting the temperature of maximum metabolic rate; however, the upper lethal temperature decreased, implying that this gastropod is still vulnerable to warming.

\section{CONCLUSION AND PERSPECTIVES}

The studies in this Special Issue not only illustrate the impacts of OA and warming on calcifiers (e.g., physiology, calcification, and survival), but also reveal potential mechanisms driving these impacts. Importantly, the adaptive response shown by some calcifiers, such as transgenerational plasticity, indicates their potential capacity to persist in future oceans. Yet, some of them (e.g., coralline algae) are predicted to be vulnerable to future seawater conditions and therefore conservation policy should

\section{REFERENCES}

Byrne, M., and Fitzer, S. (2019). The impact of environmental acidification on the microstructure and mechanical integrity of marine invertebrate skeletons. Conserv. Physiol. 7:coz062. doi: 10.1093/conphys/ coz062

Caldeira, K., and Wickett, M. E. (2005). Ocean model predictions of chemistry changes from carbon dioxide emissions to the atmosphere and ocean. J. Geophys. Res. Oceans 110:C09S4. doi: 10.1029/2004JC0 02671

Clark, M. S., Peck, L. S., Arivalagan, J., Backeljau, T., Berland, S., Cardoso, J. C. R., et al. (2020). Deciphering mollusc shell production: the roles of genetic mechanisms through to ecology, aquaculture and biomimetics. Biol. Rev. 95, 1812-1837. doi: 10.1111/brv.12640

Cornwall, C. E., Comeau, S., DeCarlo, T. M., Larcombe, E., Moore, B., Giltrow, K., et al. (2020). A coralline alga gains tolerance to ocean acidification over multiple generations of exposure. Nat. Clim. Change 10, 143-146. doi: 10.1038/s41558-019-0681-8

Di Giglio, S., Spatafora, D., Milazzo, M., M’Zoudi, S., Zito, D., Dubois, P., et al. (2020). Are control of extracellular acid-base balance and regulation of skeleton genes linked to resistance to ocean acidification in adult sea urchins? Sci. Total Environ. 720:137443. doi: 10.1016/j.scitotenv.2020. 137443

Doney, S. C., Fabry, V. J., Feely, R. A., and Kleypas, J. A. (2009). Ocean acidification: the other $\mathrm{CO}_{2}$ problem. Annu. Rev. Mar. Sci. 1, 169-192. doi: 10.1146/annurev.marine.010908.163834

Glazier, A., Herrera, S., Weinnig, A., Kurman, M., Gómez, C. E., and Cordes, E. (2020). Regulation of ion transport and energy metabolism enables certain coral genotypes to maintain calcification under experimental ocean acidification. Mol. Ecol. 29, 1657-1673. doi: 10.1111/mec.15439

Harvey, B. P., Agostini, S., Wada, S., Inaba, K., and Hall-Spencer, J. M. (2018). Dissolution: The Achilles' heel of the triton shell in an acidifying ocean. Front. Mar. Sci. 5:371. doi: 10.3389/fmars.2018.00371 be amended to protect their populations (Simon-Nutbrown et al.). More long-term, mechanistic studies using more realistic experimental design (e.g., species interactions and habitat complexity considered) are still needed to decipher the potential fate of calcifiers in future oceans (see Figure 1 for the recommended future research directions). This would allow the use of integrative analyses (e.g., Adverse Outcome Pathway framework, Ducker and Falkenberg) to provide insights into generalities in responses and underlying mechanisms, and to give directions for management and mitigation efforts.

\section{AUTHOR CONTRIBUTIONS}

All authors listed have made a substantial, direct and intellectual contribution to the work, and approved it for publication.

\section{ACKNOWLEDGMENTS}

We thank all authors and reviewers for their contributions to this Research Topic. We thank the Frontiers in Marine Science Editorial staff for their invitation and support in producing this Special Issue. Some of the images used in Figure 1 are courtesy of the Integration and Application Network, University of Maryland Center for Environmental Science (ian.umces.edu/ symbols/).
Harvey, B. P., Gwynn-Jones, D., and Moore, P. J. (2013). Meta-analysis reveals complex marine biological responses to the interactive effects of ocean acidification and warming. Ecol. Evol. 3, 1016-1030. doi: 10.1002/ ece 3.516

IPCC (2019). "Summary for policymakers," in IPCC Special Report on the Ocean and Cryosphere in a Changing Climate, eds H.-O. Pörtner, D. C. Roberts, V. Masson-Delmotte, P. Zhai, M. Tignor, E. Poloczanska, et al. Available online at: https://www.ipcc.ch/site/assets/uploads/sites/3/2019/11/03_SROCC_SPM_ FINAL.pdf

Leung, J. Y. S., Chen, Y., Nagelkerken, I., Zhang, S., Xie, Z., and Connell, S. D. (2020a). Calcifiers can adjust shell building at the nanoscale to resist ocean acidification. Small 16:2003186. doi: 10.1002/smll.2020 03186

Leung, J. Y. S., Doubleday, Z. A., Nagelkerken, I., Chen, Y., Xie, Z., and Connell, S. D. (2019). How calorie-rich food could help marine calcifiers in a $\mathrm{CO}_{2}$-rich future. Proc. R. Soc. B 286:20190757. doi: 10.1098/rspb.2019. 0757

Leung, J. Y. S., Russell, B. D., Coleman, M. A., Kelaher, B. P., and Connell, S. D. (2021). Long-term thermal acclimation drives adaptive physiological adjustments of a marine gastropod to reduce sensitivity to climate change. Sci. Total Environ. 771:145208. doi: 10.1016/j.scitotenv.2021. 145208

Leung, J. Y. S., Russell, B. D., and Connell, S. D. (2017). Mineralogical plasticity acts as a compensatory mechanism to the impacts of ocean acidification. Environ. Sci. Technol. 51, 2652-2659. doi: 10.1021/acs.est.6b04709

Leung, J. Y. S., Russell, B. D., and Connell, S. D. (2020b). Linking energy budget to physiological adaptation: how a calcifying gastropod adjusts or succumbs to ocean acidification and warming. Sci. Total Environ. 715:136939. doi: 10.1016/j.scitotenv.2020.136939

Peck, V. L., Oakes, R. L., Harper, E. M., Manno, C., and Tarling, G. A. (2018). Pteropods counter mechanical damage and dissolution through extensive shell repair. Nat. Commun. 9:264. doi: 10.1038/s41467-01702692-w 
Wang, X., Wang, M., Wang, W., Liu, Z., Xu, J., Jia, Z., et al. (2020). Transcriptional changes of Pacific oyster Crassostrea gigas reveal essential role of calcium signal pathway in response to $\mathrm{CO}_{2}$-driven acidification. Sci. Total Environ. 741:140177. doi: 10.1016/j.scitotenv.2020.14 0177

Zhao, L., Liu, B., An, W., Deng, Y., Lu, Y., Liu, B., et al. (2019). Assessing the impact of elevated $\mathrm{pCO}_{2}$ within and across generations in a highly invasive fouling mussel (Musculista senhousia). Sci. Total Environ. 689, 322-331. doi: 10.1016/j.scitotenv.2019.06.466

Conflict of Interest: The authors declare that the research was conducted in the absence of any commercial or financial relationships that could be construed as a potential conflict of interest.
Publisher's Note: All claims expressed in this article are solely those of the authors and do not necessarily represent those of their affiliated organizations, or those of the publisher, the editors and the reviewers. Any product that may be evaluated in this article, or claim that may be made by its manufacturer, is not guaranteed or endorsed by the publisher.

Copyright (c) 2021 Leung, Harvey and Russell. This is an open-access article distributed under the terms of the Creative Commons Attribution License (CC BY).

The use, distribution or reproduction in other forums is permitted, provided the original author(s) and the copyright owner(s) are credited and that the original publication in this journal is cited, in accordance with accepted academic practice. No use, distribution or reproduction is permitted which does not comply with these terms. 